Rev. Inst. Flor. v. 27 n. 1 p. $49-71$ jun. 2015

http://dx.doi.org/10.4322/rif.2015.005

ISSN impresso 0103-2674/on-line 2178-5031

\title{
ÁREAS PRIORITÁRIAS AO RESTABELECIMENTO DA CONECTIVIDADE ESTRUTURAL ENTRE FRAGMENTOS FLORESTAIS DA ZONA DE AMORTECIMENTO DA ESTAÇÃO ECOLÓGICA DE RIBEIRÃO PRETO'
}

\section{PRIORITY AREAS TO RESTORATION OF STRUCTURAL CONNECTIVITY BETWEEN FOREST FRAGMENTS OF BUFFER ZONE OF RIBEIRÃO PRETO ECOLOGICAL STATION}

\author{
Elenice Mouro VARANDA ${ }^{2,4}$; Marina Janzantti LAPENTA²; \\ Valéria Maria Melleiro GIMENEZ²; Marcela Pereira VASTERS ${ }^{2}$; Hertz Figueiredo dos SANTOS²; \\ José Ricardo BAROSELA2; Nicole Maria Marson DONADIO²; \\ Luciana de Fátima GAIOSO-RAFAEL ${ }^{2}$; Cleide de OLIVEIRA ${ }^{2,3}$
}

\begin{abstract}
RESUMO - A Estação Ecológica de Ribeirão Preto - EERP é uma Unidade de Conservação de Proteção Integral localizada no interior do Estado de São Paulo, Brasil. A Zona de Amortecimento - ZA da EERP, com $70 \%$ de sua área em zona urbana ou de expansão urbana, possui apenas $17 \%$ de cobertura vegetal distribuída em 129 manchas. A fim de subsidiar as ações de restauração florestal, foi gerado um mapa de áreas prioritárias para o restabelecimento da conectividade entre os fragmentos da ZA. Para tanto, foram considerados: a estrutura e a configuração da paisagem, a legislação ambiental e o estado de conservação das áreas remanescentes. Os resultados evidenciam a urgência de ações concretas para o restabelecimento da conectividade desta ZA pelo alto grau de fragmentação e degradação desta área. A metodologia utilizada para determinar as áreas prioritárias para conectividade foi abrangente e resultou num mapa confiável e realista, e indica que as ações de restauração florestal na ZA da EERP devem ser voltadas para duas estratégias: corredores florestais e enriquecimento de área dos fragmentos, priorizando a recuperação das matas ciliares. Esses procedimentos atuariam como facilitadores para a conectividade estrutural entre as áreas verdes próximas aos córregos e a minimização do impacto dos efeitos de borda. O resultado gerado tem a aprovação de todos os envolvidos direta ou indiretamente com a gestão da unidade de conservação e sua ZA, sendo uma excelente ferramenta auxiliar de gerenciamento e deve ser utilizado em futuros projetos de recuperação de áreas degradadas em parceria com os proprietários rurais.
\end{abstract}

Palavras-chave: Floresta Estacional Semidecidual; unidades de conservação; áreas protegidas; conectividade estrutural; zona de amortecimento; geoprocessamento.

\begin{abstract}
The Ribeirão Preto Ecological Station - EERP is a Conservation Unit of Full Protection located within the state of São Paulo, Brazil. Its Buffer Zone - BZ, with $70 \%$ of its area located in the urban or urban expansion area, has only $17 \%$ of the vegetation cover distributed in 129 vegetation patches. In order to subsidize the forest restoration actions, a map of priority areas was generated for the reestablishment of the connectivity between the fragments of BF. The considered criteria for the production of the map were: the structure and configuration of the landscape, the conservation status of the remnant and the Brazilian legislation.
\end{abstract}

$\overline{1}$ Recebido para análise em 17.01.15. Aceito para publicação em 27.04.15. Publicado on-line em 30.06.15.

${ }^{2}$ Centro de Estudo e Extensão Florestal da USP - CEEFLORUSP, Departamento de Biologia, FFCLRP, Universidade de São Paulo, Av. Bandeirantes 3900, 14040-901 Ribeirão Preto, SP, Brasil.

${ }^{3}$ Fundação para a Conservação e a Produção Florestal do Estado de São Paulo, Secretaria do Meio Ambiente do Estado de São Paulo, Rua do Horto, 931 02377-000 São Paulo, SP, Brasil.

${ }^{3}$ Autor para correspondência: Elenice Mouro Varanda- emvarand@ffclrp.usp.br 


\begin{abstract}
The results demonstrate the urgency to achieve actions to restore the connectivity of Buffer Zone in EERP, demonstrating the high degree of fragmentation and degradation of this area. The methodology used to determine the areas of priority for the connectivity was comprehensive and resulted in a reliable and realistic map. The generated map indicates that the actions of forest restoration in BZ of Ribeirão Preto Ecological Station should be focused on two strategies: forest corridors and enrichment of the fragments, prioritizing the restoration of riparian forests. These procedures would act as facilitators for the structural connectivity between the green areas nearby the streams present in BF and so minimizing the impact of the edge effects. The generated result has the approval of all those directly or indirectly involved with the management of the protected area and its BF, it is also an excellent tool to assist management and should be used in future projects of restoration in partnership with the landowners.
\end{abstract}

Keywords: Semideciduous Seasonal Forest; protected areas; conservancy; structural connectivity; buffer zone; geoprocessing.

\section{INTRODUÇ̃̃̃O}

A Mata Atlântica é considerada um dos "hotspots" mais biodiversos e ameaçados do planeta (Myers et al., 2000; Ricketts et al., 2005), pois, além do alto número de espécies endêmicas, atualmente se encontra extremamente fragmentada, cobrindo apenas $8,5 \%$ de sua área original (SOS Mata Atlântica, 2013). A situação das florestas estacionais semideciduais, que originalmente cobriam $29,5 \%$ da Mata Atlântica, é mais grave ainda, pois restam apenas $7,1 \%$ da sua área original (Ribeiro et al., 2009).

No interior do Estado de São Paulo (Sudeste do Brasil), o processo de desmatamento foi intensificado por volta de 1870 , impulsionado pela implantação da cafeicultura em larga escala. Os fragmentos que restaram das florestas estacionais semideciduais são, em sua maioria, pequenos e isolados (Viana e Pinheiro, 1998; Ribeiro et al., 2009). Por ter sido um dos principais centros produtores de café durante o final do século XIX e início do século XX, e de cana-de-açúcar a partir da segunda metade do século XX, a cobertura florestal da região de Ribeirão Preto encontra-se extremamente fragmentada, o que confere grande importância à Estação Ecológica de Ribeirão Preto - EERP, um dos maiores fragmentos da região. Porém, por estar localizada na zona de expansão urbana prevista no Plano Diretor do Município (Lei Municipal $n^{\circ}$ 501, 01/12/1995), tanto a EERP como seu entorno estão ameaçados pelo crescimento desordenado de sua área urbana.

Em paisagens fragmentadas, as populações vegetais e animais tornam-se reduzidas, os padrões de migração e dispersão são alterados, expondo os habitats a condições externas adversas, resultando na deterioração da diversidade biológica ao longo do tempo (Tilman et al., 1994; Fahrig, 2003). Além disso, quanto mais fragmentada é uma paisagem, maior é o número de extinções (Tilman et al., 1994, Lindenmayer e Fischer, 2006). Portanto, um eficiente planejamento da Zona de Amortecimento - ZA - da Estação Ecológica de Ribeirão Preto torna-se uma importante estratégia para conter e direcionar o crescimento urbano e valorizar as áreas verdes do município.

A conectividade e a manutenção dos fragmentos de Floresta Estacional Semidecidual do interior do Estado de São Paulo dependem, fundamentalmente, de ações de conservação e recuperação das Áreas de Preservação Permanente -APP e Reserva Legal -RL, que representam tanto alternativas para a preservação da biodiversidade $\mathrm{e}$ incremento da conectividade das áreas de habitat como para evitar o assoreamento, promovendo a recuperação dos rios e córregos (Naiman et al., 1993; Metzger, 2010; Borges et al., 2011). Porém, é importante selecionar criteriosamente as áreas a serem reflorestadas para melhorar a relação custo-benefício de projetos de restauração ecológica (Pardini et al., 2010).

Assim, este trabalho teve como objetivo a elaboração de um mapa de áreas prioritárias para o reestabelecimento da conectividade dos fragmentos florestais da Zona de Amortecimento - ZA da Estação Ecológica de Ribeirão Preto - EERP, aqui entendida como o entorno desta unidade onde as atividades humanas estão sujeitas a normas e restrições específicas, com o propósito de minimizar os impactos negativos sobre a mesma (Sistema Nacional de Unidades de Conservação, Art. $2^{\circ}$ inciso XVIII) (Brasil, 2000). 
O trabalho é parte do Projeto Conexão Verde, desenvolvido na EERP para subsidiar a implantação do seu Plano de Manejo, durante o qual foi promovida uma articulação institucional entre a equipe técnica (Centro de Estudo e Extensão Florestal da USP/RP - CEEFLORUSP e Fundação Florestal da Secretaria de Meio Ambiente do Estado de São Paulo), os proprietários rurais, o sindicato rural, órgãos governamentais e as lideranças locais.

A partir do mapa gerado, foi proposta uma estratégia para a minimização dos impactos da urbanização e conservação da biodiversidade através do desenvolvimento de projetos de restauração de áreas degradadas para o restabelecimento da conectividade, a proteção do solo e a recuperação dos recursos hídricos, considerando-se tanto a legislação ambiental brasileira (Brasil, 1965) como os dados relativos à estrutura e à configuração da paisagem, e o estado de conservação das áreas remanescentes obtidos através de inventários da fauna e flora e do uso de mapas temáticos. Desse modo, pretendeu-se estabelecer corredores ecológicos sugeridos pela lei do Sistema Nacional de Unidades de Conservação que assim os define: "porções de ecossistemas naturais ou seminaturais, ligando unidades de conservação, que possibilitam entre elas o fluxo de genes e o movimento da biota, facilitando a dispersão de espécies e a recolonização de áreas degradadas, bem como a manutenção de populações que demandam para sua sobrevivência áreas com extensão maior do que aquela das unidades individuais" (Sistema Nacional de Unidades de Conservação Art. $2^{\circ}$ inciso XIX) (Brasil, 2000).

\section{MATERIAL E MÉTODOS}

A Estação Ecológica de Ribeirão Preto ( $21^{\circ} 13^{\prime} 18^{\prime \prime}$ 'S e 47050'51'W), conhecida como Mata de Santa Tereza, é um remanescente de Floresta Estacional Semidecidual, com 154 ha de área. Está inserida no limite da zona de expansão urbana do município de Ribeirão Preto, Estado de São Paulo. Possui relevo suavemente ondulado e altitude média de $600 \mathrm{~m}$, com solo do tipo Latossolo vermelho. O clima é classificado como Aw pelo sistema de Köppen, com verões chuvosos e invernos secos.
Considerando o período entre 1961 e 1990 a temperatura média anual foi de $22,4{ }^{\circ} \mathrm{C}$ e a precipitação média anual foi de $1.529 \mathrm{~mm}$, com cinco meses de déficit hídrico (Empresa Brasileira de Pesquisa Agropecuária - EMBRAPA, 2011).

A Zona de Amortecimento da Estação Ecológica de Ribeirão Preto é delimitada pelas bacias dos córregos do Horto e Serraria e possui área de 2.942,98 ha e seus limites, definidos no Plano de Manejo da EERP (Leonel et al., 2010), são apresentados na Figura 1. Nesse Plano de Manejo, a Zona de Amortecimento da EERP é dividida em quatro subzonas, cada qual com normas específicas para o uso do solo dependendo da função à qual se destina. A subzona 1 é uma faixa de $50 \mathrm{~m}$ no entorno imediato da estação e se destina à arborização com espécies nativas. No seu entorno tem-se a subzona 2 com $450 \mathrm{~m}$ de largura, na qual são permitidas somente atividades agrícolas com regras específicas e construções residenciais com restrições em relação à altura das edificações, da área construída e da densidade de habitantes. $\mathrm{Na}$ subzona 3, cuja delimitação é definida pela Zona de Urbanização Controlada de acordo com Decreto Municipal, também são permitidas atividades agrícolas e construções, mas com normas menos rígidas que aquelas definidas para a subzona 2 . A subzona 4 engloba as microbacias dos córregos Serraria e do Horto, é destinada ao uso agrícola obedecendo normas que não promovam a deriva de defensiva para a Estação Ecológica.

$\mathrm{Na}$ área da ZA, são encontradas as seguintes classes de ocupação: campo sujo/úmido - áreas de pastagem abandonadas com indícios de regeneração natural e áreas brejosas com indícios de vegetação nativa herbácea ou arbustiva nas margens de cursos d'água; campo pastagem - áreas de pastagens em uso ou recentemente abandonadas; capoeira áreas com vegetação nativa em estágio inicial de regeneração; canaviais; laranjais; eucalipto; florestas - áreas de vegetação nativa em avançado estado de regeneração e florestas maduras; reservatórios de água - lagos naturais e reservatórios artificiais; anel viário de Ribeirão Preto; sede rural - sedes de fazendas e pequenas construções rurais, incluindo área de entorno das residências, como quintais e pomares; área institucional antenas institucionais e sede da EERP; área urbana - bairros, loteamentos e áreas de lazer da cidade de Ribeirão Preto. 


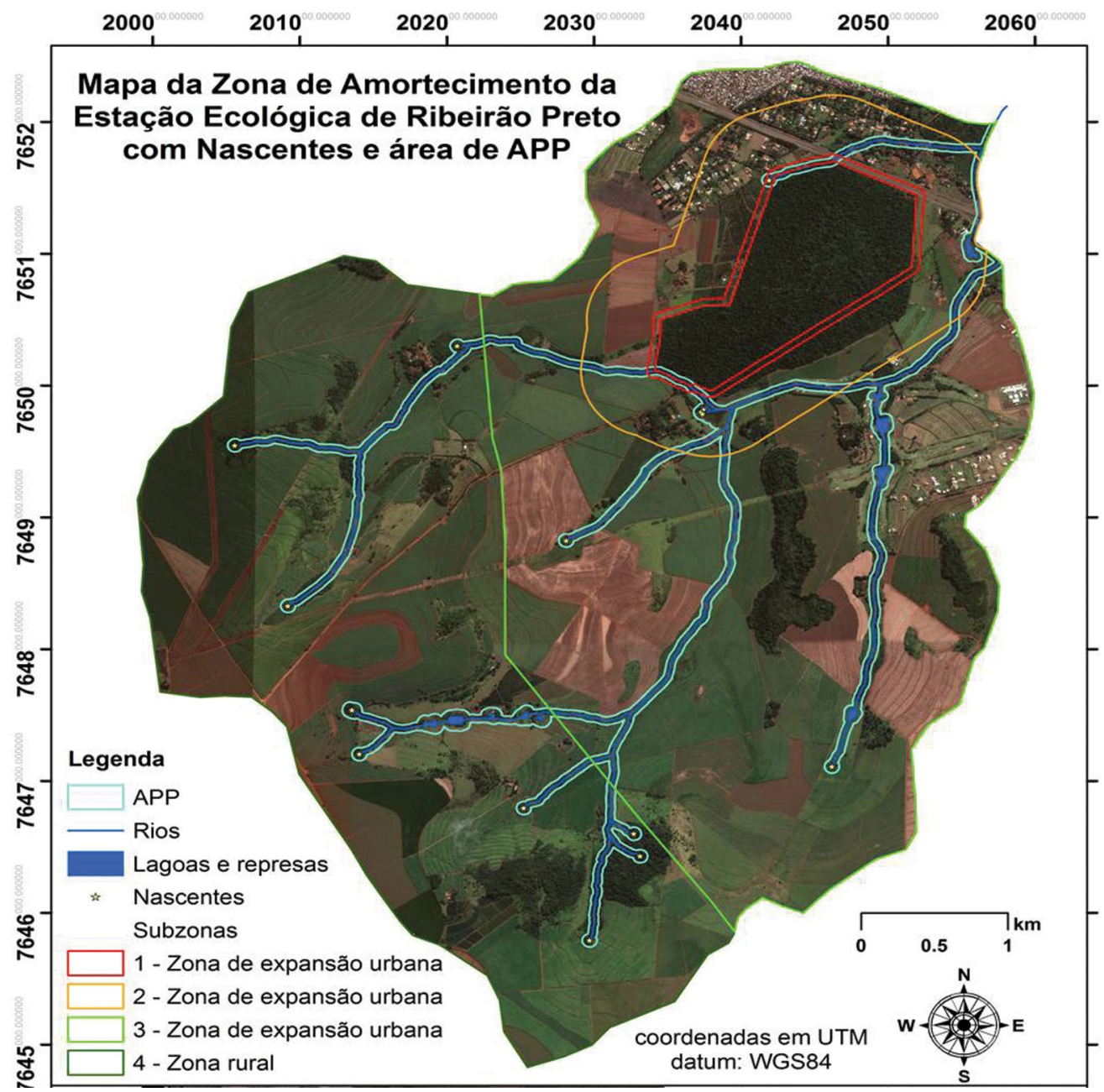

Figura 1. Localização da Zona de Amortecimento (limite em amarelo) da Estação Ecológica de Ribeirão Preto (EERP, limite em vermelho), Estado de São Paulo, Brasil. Mapa retirado do Plano de Manejo da Estação Ecológica de Ribeirão Preto (Leonel et al., 2010).

Figure 1. Location of the Buffer Zone (yellow edges) of the Ribeirão Preto Ecological Station (red edges), São Paulo state, Brazil. Map taken from the Management Plan of the Ribeirão Preto Ecological Station (Leonel et al., 2010),

Para a caracterização da biodiversidade da ZA, foram realizados levantamentos de vertebrados terrestres e da flora, especialmente do componente arbóreo, nos quatro maiores fragmentos florestais denominados 1,2 , 3a e 3b, indicados na Figura 2. Os dados amostrados nos fragmentos $3 \mathrm{a}$ e $3 \mathrm{~b}$ foram analisados conjuntamente devido à sua proximidade.

O inventário da fauna de vertebrados terrestres foi realizado entre os meses de janeiro e março de 2011. As amostragens da mastofauna de médio-grande porte foram realizadas através de armadilhas fotográficas e iscas, com esforço amostral de 51 armadilhas/ noite. Também foram considerados registros ocasionais, como registros visuais, sonoros, de pegadas e de fezes, além de entrevistas com moradores locais. O levantamento da avifauna foi realizado através de caminhadas por trilhas já existentes nos fragmentos, com esforço amostral de 15 visitas e 38h50min de observação. O levantamento de répteis e anfíbios foi realizado a partir de busca direta com $42 \mathrm{~h}$ de amostragem e de 20 transectos de tamanhos variados. Em ambos os casos, foram registrados avistamentos, vocalizações, ninhos de espumas, pegadas e tocas. 


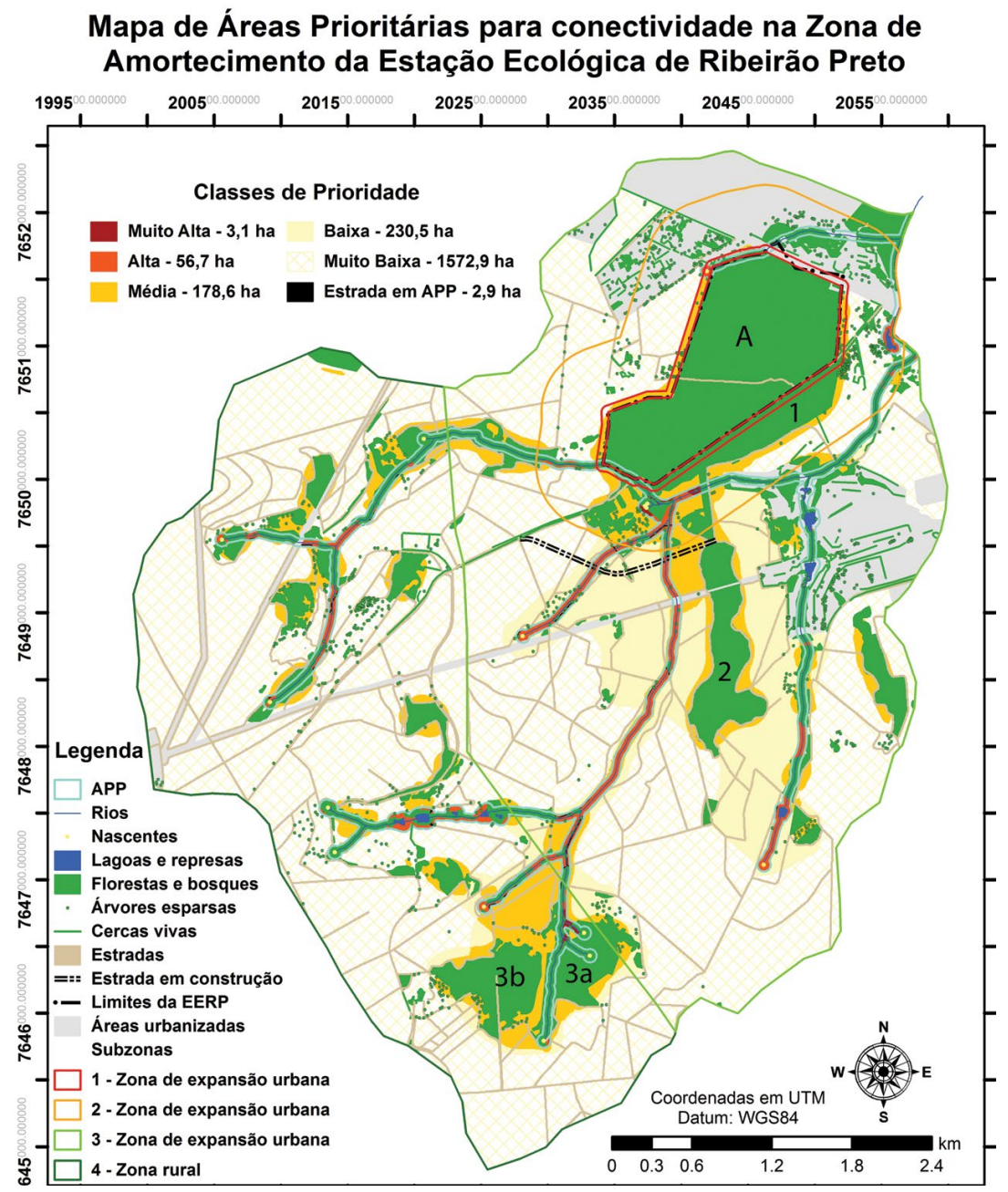

Figura 2. Mapa de áreas prioritárias para o restabelecimento da conectividade estrutural entre os fragmentos florestais presentes na Zona de Amortecimento da Estação Ecológica de Ribeirão Preto. A- fragmento que compõe a Estação Ecológica de Ribeirão Preto. 1, 2, 3a e 3b-fragmentos amostrados neste estudo.

Figure 2. Map of priority areas for the reestablishment of the connectivity between forest remnants of the Buffer Zone of the Ribeirão Preto Ecological Station. A- Ribeirão Preto Ecological Station. 1, 2, 3a and 3b - forest remnants sampled during the study.

O levantamento expedito das espécies arbóreas ocorrentes nos fragmentos 2 , $3 \mathrm{a}$ e $3 \mathrm{~b}$ foi realizado através de caminhadas na borda de todos os fragmentos, além de quatro trilhas orientadas no sentido borda-centro. Para o fragmento 1 foram utilizados, para compor a lista de espécies, os dados de levantamento fitossociológico realizado por Camargo (2008).
As áreas prioritárias para restauração foram selecionadas através do cruzamento de três mapas temáticos (bases 1, 2 e 3) utilizando programação em LEGAL (Linguagem Espacial para Geoprocessamento Algébrico) no programa SPRING (Camara et al., 1996). Foram definidas classes de prioridade muito alta, alta, média, baixa e muito baixa, considerando-se a sobreposição de indicações de cada uma das três bases segundo as regras apresentadas na Tabela 1. 
Tabela 1. Regras para a definição das áreas prioritárias considerando as três bases utilizadas: base 1 - recuperação de Áreas de Preservação Permanente; base 2 - recuperação de áreas com maior resiliência; base 3 -recuperação da conectividade entre os maiores fragmentos da ZA.

Table 1. Rules for the definition of the priority areas considering the three bases used: base 1 - recovering of Permanent Preservation Areas; base 2 - recovery of higher resilient areas; base 3 - recovering of the connectivity among larger forest fragments of BZ.

\begin{tabular}{cc}
\hline Prioridade & Sobreposição das Indicações \\
\hline Muito alta & bases 1 e 2 e 3 \\
Alta & apenas base 1 \\
Média & apenas base 2 \\
Baixa & apenas base 3 \\
Muito baixa & sem indicação \\
\hline
\end{tabular}

A base 1 representa os limites legais das Áreas de Proteção Permanente - APPs relacionadas aos recursos hídricos, segundo a antiga legislação ambiental à época da realização deste trabalho. O Código Florestal Brasileiro foi recentemente alterado, sendo o atual (Lei 12.651/2012) (Brasil, 2012) menos restritivo que o anterior (Lei 4.771/1965) (Brasil, 1965) e, portanto, menos eficiente do ponto de vista ambiental (Metzger, 2010; Metzger et al., 2010). Optamos por manter as análises feitas com base no antigo código florestal, que prevê APPs de $30 \mathrm{~m}$ ao longo dos rios e $50 \mathrm{~m}$ ao redor de nascentes, como apresentado nos relatórios finais à Unidade de Conservação. A drenagem foi extraída de cartas topográficas do Instituto Geográfico e Geológico - IGC na escala 1:10.000 de 1983/84, e corrigida com base na imagem do Satélite Geoeye-1 e em visitas a campo. As APPs já ocupadas por vegetação nativa foram subtraídas dessa base e as restantes foram indicadas para restauração. A restauração de APPs foi considerada prioritária por combinar aumento das áreas de habitat, aumento de conectividade entre os fragmentos da ZA, proteção dos recursos hídricos e possuir respaldo na legislação.

A base 2 foi gerada pela análise "moving windows" do programa FRAGSTAT (McGarigal et al., 2002) e indica para restauração áreas da matriz que apresentaram pelo menos $30 \%$ de áreas verdes com espécies arbóreas considerando um raio de 150 m. Segundo Pardini et al. (2010), essas áreas são mais adequadas para projetos de reflorestamento por estarem menos isoladas e, portanto, possuírem maior resiliência, tornando mais viável financeiramente o processo de recuperação florestal.
A base 3 foi proposta com o objetivo de promover o aumento do fluxo entre os fragmentos e minimizar os impactos dos efeitos de borda nos maiores fragmentos da ZA. As árvores isoladas, cercas vivas, áreas urbanas, estradas e carreadores de cana também foram digitalizadas e incluídas no mapa de áreas prioritárias.

Para a execução do projeto houve o envolvimento de organizações sociais, políticas e ambientais com interesse no uso e ocupação do solo na ZA. Aos proprietários de áreas localizadas na ZA que participaram, foram propostos projetos individuais de recuperação de suas áreas.

\section{RESULTADOS E DISCUSSÃO}

A ZA possui 505,34 ha $(17,7 \%)$ de sua área total ocupada por áreas verdes (habitat), distribuídos em 129 manchas de vegetação com média de 3,8 $\pm 12,8$ ha. Dos fragmentos encontrados, $87,5 \%$ têm área igual ou menor que 5 ha, com apenas seis fragmentos maiores que 20 ha, incluindo a Estação Ecológica de Ribeirão Preto (Figura 1). Os fragmentos de mata nativa em diferentes estádios de conservação somaram $98,9 \%$ do total de áreas verdes e as manchas de pomar e silvicultura somaram 1,1\%. A distância de cada fragmento ao seu vizinho mais próximo varia de 8 a $626 \mathrm{~m}$, com média de 71,7 $\pm 93,4 \mathrm{~m}$. A baixa proporção de habitat, a pequena área média e o alto grau de isolamento dos fragmentos indicam a intensa fragmentação da vegetação da ZA. 
Nos fragmentos 1, 2 e 3, foram amostradas 247 espécies, sendo 123 espécies de vertebrados e 124 espécies vegetais. $\mathrm{O}$ fragmento 1 apresentou o maior número de espécies animais e vegetais, o que deve estar relacionado à sua elevada riqueza de espécies arbóreas (Tabela 2, listas das espécies no Anexo I, Tabelas II.1 a II.4) devido à sua localização contígua à EERP da qual é separado somente por uma estrada que foi fechada ao tráfego de veículos recentemente.

Nos fragmentos 1, 2 e 3, foram registradas 14 espécies de mamíferos pertencentes a sete ordens e 10 famílias, 96 espécies de aves (18 ordens e 33 famílias) e 13 espécies da herpetofauna de duas ordens e quatro famílias.
Das aves, 80 espécies ocupavam efetivamente os remanescentes florestais amostrados, enquanto as demais foram registradas sobrevoando entre os fragmentos.

O inventário florístico revelou a presença de 124 espécies, distribuídas em 87 gêneros e 41 famílias, das quais cinco são exóticas não invasoras e três são exóticas invasoras. As famílias mais frequentes foram Meliaceae, Fabaceae/Mimosoidea, Rutaceae, Euphorbiaceae, Fabaceae/Caesalpinioidea e Malvaceae. Entre as classes sucessionais, a maioria das espécies registradas são secundárias iniciais ou pioneiras e a forma de dispersão dominante de suas sementes é a zoocórica (Tabela 3).

Tabela 2. Riqueza de espécies registrada por fragmento e por grupo de organismo.

Table 2. Species richness recorded in each fragment and group of organism.

\begin{tabular}{lcccc}
\hline Grupo & Fragmento 1 & Fragmento 2 & Fragmento 3 & Total \\
\hline Mastofauna & 3 & 8 & 14 & 14 \\
Avifauna & 75 & 73 & 65 & 96 \\
Herpetofauna & 10 & 0 & 4 & 13 \\
Flora arbórea & 94 & 32 & 21 & 124 \\
\hline Total & 182 & 113 & 104 & 247 \\
\hline
\end{tabular}

Tabela 3. Número total - Nsp. e frequência relativa - Freq Rel de espécies por classe sucessional e síndrome de dispersão. Legenda para atributos Classe Sucessional: P - pioneira, Si - secundária inicial; $\mathrm{St}$ - secundária tardia; C- climácica; U - umbrófila; Nclas - não classificada. Legenda atributos Síndrome de Dispersão: Ane - anemocórica; Zoo - zoocórica; Auto - autocórica; Baro - barocórica.

Table 3. Total number - Nsp. and relative frequency - Freq Rel of tree species in each successional class and dispersion syndrome. Successional groups: P - pioneer; Si - early secondary; St - late secondary; C - climax; U- ombrophilous. Nclas - not classified. Dispersal Syndromes: Ane - anemochorous; Zoo - zoochorous; Auto - autochorous; Baro - barochorous.

\begin{tabular}{llllllllllll}
\hline & \multicolumn{1}{c}{ Classes Sucessional } & \multicolumn{9}{c}{ Síndrome de Dispersão } \\
& $\mathrm{P}$ & $\mathrm{Si}$ & $\mathrm{St}$ & $\mathrm{C}$ & $\mathrm{U}$ & Nclas & Ane & Zoo & Auto & Baro & Ncls \\
\hline Nsp & 30 & 53 & 17 & 5 & 7 & 12 & 30 & 63 & 19 & 1 & 11 \\
Freq Re. & 24,2 & 42,7 & 13,7 & 4,0 & 5,6 & 9,7 & 24,2 & 50,8 & 15,3 & 0,8 & 8,9 \\
\hline
\end{tabular}


As classes de prioridade de restauração florestal "muito alta" e "alta" somam 60 ha de área e coincidem com as APPs (Figura 2). As áreas com prioridade de restauração "média" somam 177,9 ha e são eficazes para mitigar os impactos dos efeitos de borda, pois diminuem a relação perímetro/área e aumentam o tamanho dos fragmentos. A restauração florestal, indicada para as áreas com as classes de prioridade "muito alta", "alta" e "média", representaria a recuperação de aproximadamente $8 \%$ da área da ZA, totalizando cerca de $25 \%$ de habitat, ao invés dos atuais 17,7\%. Além disso, a Figura 2 mostra que um plano de reflorestamento dessas áreas conectaria a maioria dos fragmentos da ZA. O mapa de áreas prioritárias para a conectividade na ZA apresenta diretrizes realistas e factíveis, considerando que o município de Ribeirão Preto está em franco crescimento (Instituto Brasileiro de Geografia e Estatística - IBGE, 2010).

Algumas espécies de vertebrados e de árvores são boas indicadoras da qualidade ambiental (Willis, 1979; Loiselle e Blake, 1992; Groom et al., 2006; Loebmann, 2005; Reis et al., 2011; Wright, et al., 2000). Os dados levantados mostram que a ZA apresenta-se extremamente fragmentada e com uma biodiversidade típica de áreas degradadas. Apesar da maioria dos vertebrados registrados ser generalista e pouco sensível a alterações ambientais, também foram registradas espécies que se encontram em listas das ameaçadas de extinção, como a jaguatirica (Leopardus pardalis), o lobo-guará (Chrysocyon brachyurus), a onça-parda (Puma concolor), a jandaia-de-testa-vermelha (Aratinga auricapillus) e o pica-pau-de-topete-vermelho (Campephilus melanoleucos). Também foram encontradas espécies vegetais especialistas de ambientes florestais com destaque para o jaborandi (Pilocarpus microphyllus), espécie de arbusto ameaçado de extinção, além de espécies vulneráveis à extinção, como o guaritá (Astronium graveolens), o ipê-tabaco (Zeyheria tuberculosa) e o cedro (Cedrella fissilis) (Martinelli e Moraes, 2013). Assim, a recuperação das áreas com prioridades "alta" e "muito alta" de restauração (Figura 2) pode colaborar na manutenção dessas espécies na ZA, reduzindo o efeito do débito de extinção (Tilman et al., 1994).

O mapa de prioridades apresenta algumas informações altamente detalhadas e raras em mapeamentos similares e uma delas é a extensão de estradas em APPs que ocupam 3,4 ha (2,23\% do total) das mesmas e que, na maioria dos casos, correm paralelas aos rios. Esses trechos de estrada funcionam como potenciais fontes de sedimentos que contribuem para o assoreamento dos rios. Portanto, enfatiza-se a necessidade de se redesenhar essas estradas, que são na maioria dos casos carreadores de cana, de forma que cruzem APPs apenas perpendicularmente em alguns poucos pontos estratégicos para transpor os córregos.

Outra informação relevante é relacionada às árvores isoladas e às cercas vivas, elementos importantes para aumentar a permeabilidade da matriz (Manning et al., 2006). O baixo número de árvores isoladas não permite que esses elementos tenham um papel ecológico significativo na ZA. A ampliação da arborização das estradas e carreadores existentes, exceto aqueles localizados em APPs que devem ser reflorestados, apresenta-se como uma alternativa simples e economicamente viável para aumentar a permeabilidade da matriz na área estudada.

Para promover o aumento do fluxo entre os fragmentos e minimizar os impactos dos efeitos de borda nos maiores fragmentos da ZA, foi proposta a conexão via APP ciliar entre os fragmentos 1 e $3 \mathrm{~b}$ e $o$ aumento de área para os fragmentos $1,2,3 \mathrm{a}$ e $3 \mathrm{~b}$.

A implantação de corredores tem sido uma importante estratégia para a conservação da biodiversidade (Rosenberg et al., 1997; Fischer et al., 2006), pois aumentam a troca de indivíduos entre populações (Haddad, 1999; Tewksbury et al., 2002, Metzger, 2010) e a persistência destas nos fragmentos, diminuindo as taxas de extinção local e aumentando as taxas de colonização. Os corredores são fundamentais para um fluxo de organismos que seria inexistente em áreas onde a matriz circundante é pouco permeável, como a encontrada na ZA (Fischer et al., 2006).

Os corredores ripários apresentados na Figura 2, que correspondem às classes de prioridade "muito alta" e "alta", são relativamente estreitos (60 m). Esses corredores são facilmente dominados pelo efeito de borda e garantem apenas a conservação de espécies generalistas e resistentes a ambientes alterados (Lopes et al., 2009; Metzger, 2010). Ainda assim, sua presença é significativa para a manutenção da biodiversidade, a proteção dos recursos hídricos e a manutenção de polinizadores (Fischer et al., 2006; Borges et al., 2011). 
Segundo Haddad (1999), corredores dentro de qualquer paisagem têm efeitos positivos, negativos ou neutros para diferentes espécies, pois sua eficácia é específica para as espécies e a paisagem. É importante monitorar o fluxo de organismos e o uso do solo na região-alvo, para se avaliar como as diferentes espécies (especialistas e generalistas) estão respondendo às alterações na configuração da paisagem provocadas pela implantação de corredores florestais. Em pequenos fragmentos, como é o caso dos mapeados, investimentos no aumento de área são mais efetivos que corredores, caso o aumento seja suficiente para que o fragmento ultrapasse o tamanho mínimo requerido para manter populações viáveis das espécies-alvo (Falcy e Estades, 2007).

Ainda, o custo-benefício de se reflorestar varia de acordo com a quantidade de vegetação remanescente no entorno da área a ser reflorestada, independentemente se a estratégia escolhida for a formação de corredores ou o aumento de área (Pardini et al., 2010). Desse modo, os reflorestamentos devem ser implantados em áreas com porcentagem de habitat relativamente alta e com maior capacidade de resiliência (Pardini et al., 2010), ou em áreas ciliares, especialmente importantes para a manutenção dos recursos hídricos (Naiman et al., 1993; Metzger, 2010; Borges et al., 2011).

Assim, o mapa de áreas prioritárias indica a instalação de corredores florestais aproveitando os locais em que a recuperação florestal é obrigatória por lei (APPs, Figura 2), minimizando o custo de adequação para os proprietários. Ao mesmo tempo, as áreas com prioridade "média" dão ênfase ao aumento das áreas dos fragmentos e à redução da relação perímetro/área, o que torna os fragmentos menos sujeitos aos efeitos de borda.

Os proprietários que aderiram ao Projeto Conexão Verde receberam projetos individuais de restauração elaborados com base nos levantamentos realizados e na legislação (especialmente na Resolução 08/SMA/SP) para serem desenvolvidos em áreas de suas propriedades, que foram indicadas no mapa. No Anexo II, encontra-se o modelo de formulário utilizado para a preparação de tais projetos.

No Plano de Manejo da EERP (Leonel et al., 2012), o Projeto Conexão Verde aparece como Encarte 6, em suas páginas 203 a 215. Assim, esse Plano indica a necessidade de conexão da UC com remanescentes da Zona de Amortecimento, incorporando as propostas e conclusões do Projeto Conexão Verde como estratégias adequadas para o seu manejo e seu mapa de prioridades como base para as ações na ZA.

\section{CONCLUSÕES}

Pode-se considerar que esse trabalho, previsto pelo Plano de Manejo da EERP, alcançou a desejável articulação institucional entre equipe técnica, proprietários rurais, sindicato rural, órgãos governamentais e lideranças locais. Os resultados obtidos tiveram a aprovação de todos os envolvidos direta ou indiretamente com a gestão da Unidade de Conservação e sua ZA, sendo uma excelente ferramenta auxiliar de gerenciamento e podem ser utilizados em futuros projetos de recuperação das áreas degradadas em parceria com os proprietários rurais.

A opção sugerida pelo Projeto Conexão Verde de que devem ser usadas técnicas para a restauração em detrimento daquelas de recuperação, entendidas de acordo com a Lei do Sistema Nacional de Unidades de Conservação, foi acatada e aprovada em seu Plano de Manejo.

A partir do mapa gerado foi possível propor estratégias para a minimização dos impactos da urbanização na conservação da biodiversidade, na proteção do solo e na recuperação dos recursos hídricos. Assim, as ações de recuperação devem priorizar áreas próximas ou inseridas nos polígonos das classes de prioridade "muito alta", "alta" ou "média" e deve-se salientar a urgência para o desenvolvimento de ações concretas para o restabelecimento da conectividade dos fragmentos da ZA da EERP, evidenciada pelo alto grau de fragmentação e isolamento das áreas verdes. Para tanto, devem ser incentivados projetos de manejo das áreas degradadas para o restabelecimento da conectividade, o que já foi iniciado através da entrega de propostas individuais aos proprietários que aderiram ao Projeto Conexão Verde para a restauração das áreas indicadas em suas propriedades.

Ainda, deve ser salientado que a metodologia utilizada para determinar as áreas prioritárias para conectividade foi abrangente e resultou num mapa confiável e realista. 


\section{ANEXO I \\ Espécies da flora e da fauna registradas na área da Zona de Amortecimento da Estação Ecológica de Ribeirão Preto}

Tabela II.1. Mastofauna registrada na área da Zona de Amortecimento da Estação Ecológica de Ribeirão Preto. Foi utilizada a nomenclatura de Wilson e Reeder (2005), Reis et al. (2011). Status de conservação: VU - vulnerável, AM - ameaçada, EX - espécie exótica (introduzida de outro país). *São Paulo (2014), **Brasil (2014),

Table II.1. Mammalian fauna recorded in the Buffer Zone area of the Ribeirão Preto Ecological Station. Nomenclatures used are in accordance to Wilson and Reeder (2005), Reis et al. (2011). Conservation status: VU - vulnerable, AM - threatened, EX - Exotic species, introduced from another country. *São Paulo, 2014, **Brazil (2014).

\begin{tabular}{|c|c|c|c|}
\hline \multicolumn{2}{|c|}{ ORDEM/Família } & Espécies & Nomes populares \\
\hline \multicolumn{4}{|c|}{ DIDELPHIMORPHIA } \\
\hline & Didelphidae & Didelphis albiventris (Lund, 1840) & gambá-de-orelha-branca \\
\hline \multicolumn{4}{|l|}{ CINGULATA } \\
\hline & Dasypodidae & Dasypus novemcinctus (Lund, 1758) & tatu galinha \\
\hline & & Euphractus sexcinctus (Lund, 1758) & tatu-peba \\
\hline \multicolumn{4}{|l|}{ PRIMATES } \\
\hline & Cebidae & Callithrix penicillata (É. Geoffroy, 1812) & sagui-de-tufo-preto \\
\hline & & Sapajus nigritus (Goldfuss, 1809) & macaco-prego \\
\hline \multicolumn{4}{|l|}{ CARNIVORA } \\
\hline & Felidae & Leopardus pardalis (Linnaeus, 1758) AM* & jaguatirica \\
\hline & & Puma yagouaroundi (É. Geoffroy, 1803) VU** & gato-mourisco \\
\hline & & Puma concolor (Linnaeus, 1771) VU** AM* & onça-parda \\
\hline \multicolumn{4}{|l|}{ CARNIVORA } \\
\hline & Canidae & Cerdocyon thous (Linnaeus, 1766) & cachorro-do-mato \\
\hline \multicolumn{4}{|l|}{ ARTIODACTYLA } \\
\hline & Cervidae & Mazama gouazoubira (Fischer, 1814) & veado-catingueiro \\
\hline \multicolumn{4}{|l|}{ ARTIODACTYLA } \\
\hline & Tayassuidae & Pecari tajacu (Linnaeus, 1758) & cateto \\
\hline \multicolumn{4}{|l|}{ RODENTIA } \\
\hline & Caviidae & Hydrochoerus hydrochaeris (Linnaeus, 1766) & capivara \\
\hline \multicolumn{4}{|l|}{ RODENTIA } \\
\hline & Dasyproctidae & Dasyprocta azarae (Lichtenstein,1823) & cutia \\
\hline \multirow[t]{2}{*}{ LAGOMORPHA } & & Lepus europaeus (Pallas, 1778) EX & lebre-europeia \\
\hline & Leporidae & & \\
\hline
\end{tabular}


VARANDA, E.M. et al. Conectividade em ZA de UC

Tabela II.2. Avifauna registrada na área da Zona de Amortecimento da Estação Ecológica de Ribeirão Preto. Status de conservação: VU - vulnerável, PA - provavelmente/quase ameaçada. *São Paulo (2014), **International Union for Conservation of Nature - IUCN (2014).

Table II.2. Avifauna recorded in the Buffer Zone area of the Ribeirão Preto Ecological Station. Conservation status: VU - vulnerable, PA - probably/near threatened. *SP, 2014; **International Union for Conservation of Nature - IUCN (2014).

\begin{tabular}{|c|c|c|}
\hline ORDEM/Família & Espécies & Nomes populares \\
\hline \multicolumn{3}{|l|}{ TINAMIFORMES } \\
\hline Tinamidae & Crypturellus parvirostris (Wagler, 1827) & inhambu-chororó \\
\hline \multicolumn{3}{|l|}{ ANSERIFORMES } \\
\hline Anatidae & Dendrocygna autumnalis (Linnaeus, 1758) & asa-branca \\
\hline & Amazonetta brasiliensis (Gmelin, 1789) & pé-vermelho \\
\hline \multicolumn{3}{|l|}{ ELECANIFORMES } \\
\hline Ardeidae & Bubulcus ibis (Linnaeus, 1758) & garça-vaqueira \\
\hline & Ardea alba (Linnaeus, 1758) & garça-branca-grande \\
\hline & Syrigma sibilatrix (Temminck, 1824) & maria-faceira \\
\hline \multicolumn{3}{|l|}{ THRESKIORNITHIDAE } \\
\hline Threskiornithidae & Mesembrinibis cayennensis (Gmelin, 1789) & coró-coró \\
\hline \multicolumn{3}{|l|}{ CATHARTIFORMES } \\
\hline Cathartidae & Cathartes aura (Linnaeus, 1758) & urubu-de-cabeça-vermelha \\
\hline & Coragyps atratus (Bechstein, 1793) & urubu-de-cabeça-preta \\
\hline \multicolumn{3}{|l|}{ ACCIPITRIFORMES } \\
\hline Accipitridae & Ictinia plumbea (Gmelin, 1788) & sovi \\
\hline & Rupornis magnirostris (Gmelin, 1788) & gavião-carijó \\
\hline & Buteo brachyurus Vieillot, 1816 & gavião-de-cauda-curta \\
\hline \multicolumn{3}{|l|}{ FALCONIFORMES } \\
\hline Falconidae & Caracara plancus Miller, 1777 & caracará \\
\hline & Milvago chimachima Vieillot, 1816 & carrapateiro \\
\hline \multicolumn{3}{|l|}{ GRUIFORMES } \\
\hline Rallidae & Aramides cajanea (Müller, 1776) & saracura-três-potes \\
\hline \multicolumn{3}{|l|}{ CARIAMIFORMES } \\
\hline Cariamidae & Cariama cristata (Linnaeus, 1766) & seriema \\
\hline \multicolumn{3}{|l|}{ CHARADRIIFORMES } \\
\hline Charadriidae & Vanellus chilensis (Molina, 1782) & quero-quero \\
\hline \multicolumn{3}{|l|}{ COLUMBIFORMES } \\
\hline Columbidae & Columbina talpacoti (Temminck, 1810) & rolinha-roxa \\
\hline & Columbina squammata Lesson, 1831 & fogo-apagou \\
\hline & Patagioenas picazuro Temminck, 1813 & pombão \\
\hline & Patagioenas cayennensis (Bonnaterre, 1792) & pomba-galega \\
\hline & Zenaida auriculata (Des Murs, 1847) & pomba-de-bando \\
\hline & Leptotila verreauxi (Bonaparte, 1855) & juriti-pupu \\
\hline
\end{tabular}

to be continued 
continuação - Tabela II.2

continuation - Table II.2

\begin{tabular}{|c|c|c|}
\hline ORDEM/Família & Espécies & Nomes populares \\
\hline \multicolumn{3}{|l|}{ PSITTACIFORMES } \\
\hline \multirow[t]{6}{*}{ Psittacidae } & Aratinga leucophthalma (Statius Müller, 1776) & periquitão-maracanã \\
\hline & Aratinga auricapillus (Kuhl, 1820) PA** & jandaia-de-testa-vermelha \\
\hline & Aratinga aurea (Gmelin, 1788) & periquito-rei \\
\hline & Forpus xanthopterygius (Spix, 1824) & tuim \\
\hline & Brotogeris chiriri (Vieillot, 1818) & periquito-de-encontro-amarelo \\
\hline & Amazona amazonica (Linnaeus, 1766) VU* & curica \\
\hline \multicolumn{3}{|l|}{ CUCULIFORMES } \\
\hline \multirow[t]{3}{*}{ Cuculidae } & Piaya cayana (Linnaeus, 1766) & alma-de-gato \\
\hline & Coccyzus melacoryphus Vieillot, 1817 & papa-lagarta-acanelado \\
\hline & Crotophaga ani Linnaeus, 1758 & anu-preto \\
\hline \multicolumn{3}{|l|}{ STRIGIFORMES } \\
\hline \multirow[t]{2}{*}{ Tytonidae } & Tyto alba (Scopoli, 1769) & coruja-da-igreja \\
\hline & Athene cunicularia (Molina, 1782) & coruja-buraqueira \\
\hline \multicolumn{3}{|l|}{ CAPRIMULGIFORMES } \\
\hline \multirow[t]{3}{*}{ Nyctibiidae } & Nyctibius griseus (Gmelin, 1789) & mãe-da-lua \\
\hline & Hydropsalis albicollis (Gmelin, 1789) & bacurau \\
\hline & Hydropsalis torquata (Gmelin, 1789) & bacurau-tesoura \\
\hline \multicolumn{3}{|l|}{ APODIFORMES } \\
\hline \multirow[t]{5}{*}{ Apodidae } & Streptoprocne sp Oberholser, 1906 & taperuçu \\
\hline & Chaetura meridionalis Hellmayr, 1907 & andorinhão-do-temporal \\
\hline & Tachornis squamata (Cassin, 1853) VU* & andorinhão-do-buriti \\
\hline & Eupetomena macroura Gmelin, 1788 & beija-flor-tesoura \\
\hline & Amazilia Láctea (Lesson, 1829) & beija-flor-de-peito-azul \\
\hline \multicolumn{3}{|l|}{ PICIFORMES } \\
\hline Ramphastidae & Ramphastos toco Statius (Müller, 1776) & tucanuçu \\
\hline \multicolumn{3}{|l|}{ PICIFORMES } \\
\hline \multirow[t]{7}{*}{ Picidae } & Picumnus albosquamatus (D’Orbigny, 1840) & pica-pau-anão-escamado \\
\hline & Melanerpes candidus (Otto, 1796) & pica-pau-branco \\
\hline & Veniliornis passerinus (Linnaeus, 1766) & picapauzinho-anão \\
\hline & Colaptes melanochloros (Gmelin, 1788) & pica-pau-verde-barrado \\
\hline & Colaptes campestres (Vieillot, 1818) & pica-pau-do-campo \\
\hline & Dryocopus lineatus (Linnaeus, 1766) & pica-pau-de-banda-branca \\
\hline & Campephilus melanoleucos (Gmelin, 1788) VU* & pica-pau-de-topete-vermelho \\
\hline
\end{tabular}

continua

to be continued 
VARANDA, E.M. et al. Conectividade em ZA de UC

continuação - Tabela II.2

continuation - Table II.2

\begin{tabular}{|c|c|}
\hline ORDEM/Família & Espécies \\
\hline \multicolumn{2}{|l|}{ PASSERIFORMES } \\
\hline \multirow[t]{5}{*}{ Thamnophilidae } & Taraba major (Vieillot, 1816) \\
\hline & Thamnophilus doliatus (Linnaeus, 1764) \\
\hline & Thamnophilus pelzelni (Hellmayr, 1924) \\
\hline & Dysithamnus mentalis (Temminck, 1823) \\
\hline & Herpsilochmus atricapillus (Pelzeln, 1868) \\
\hline \multicolumn{2}{|l|}{ PASSERIFORMES } \\
\hline Dendrocolaptidae & Lepidocolaptes angustirostris (Vieillot, 1818) \\
\hline \multicolumn{2}{|l|}{ PASSERIFORMES } \\
\hline \multirow[t]{2}{*}{ Furnariidae } & Furnarius rufus (Gmelin, 1788) \\
\hline & Synallaxis frontalis (Pelzeln, 1859) \\
\hline \multicolumn{2}{|l|}{ PASSERIFORMES } \\
\hline Rynchocyclidae & Todirostrum cinereum (Linnaeus, 1766) \\
\hline \multicolumn{2}{|l|}{ PASSERIFORMES } \\
\hline \multirow[t]{11}{*}{ Tyrannidae } & Elaenia flavogaster (Thunberg, 1822) \\
\hline & Camptostoma obsoletum (Temminck, 1824) \\
\hline & Colonia colonus (Vieillot, 1818) \\
\hline & Pitangus sulphuratus (Linnaeus, 1766) \\
\hline & Myiodynastes maculatus (Statius Müller, 1776) \\
\hline & Megarynchus pitangua (Linnaeus, 1766) \\
\hline & Empidonomus varius (Vieillot, 1818) \\
\hline & Tyrannus albogularis (Burmeister, 1856) \\
\hline & Tyrannus melancholicus (Vieillot, 1819) \\
\hline & Myiarchus ferox (Gmelin, 1789) \\
\hline & Myiarchus tyrannulus (Statius Muller, 1776) \\
\hline
\end{tabular}

PASSERIFORMES

Vireonidae Cyclarhis gujanensis (Gmelin, 1789)

Vireo olivaceus (Linnaeus, 1766)

choró-boi

choca-barrada

choca-do-planalto

choquinha-lisa

chorozinho-de-chapéu-preto

arapaçu-de-cerrado

joão-de-barro

petrim

ferreirinho-relógio

guaracava-de-barriga-amarela

risadinha

viuvinha

bem-te-vi

bem-te-vi-rajado

neinei

peitica

suiriri-de-garganta-branca

suiriri

maria-cavaleira

maria-cavaleira-

-de-rabo-enferrujado

pitiguari

juruviara

PASSERIFORMES

Hirundinidae Pygochelidon cyanoleuca (Vieillot, 1817)

PASSERIFORMES

Troglodytidae Troglodytes musculus (Naumann, 1823)

Cantorchilus leucotis (Lafresnaye, 1845)

PASSERIFORMES

Turdidae Turdus leucomelas (Vieillot, 1818)

Turdus amaurochalinus (Cabanis, 1850)

andorinha-pequena-de-casa

corruíra

garrinchão-de-barriga-vermelha

sabiá-barranco

sabiá-poca

continua

to be continued 
continuação - Tabela II.2

continuation - Table II.2

\begin{tabular}{|c|c|c|c|}
\hline ORDEM/Fa & nília & Espécies & Nomes populares \\
\hline \multicolumn{4}{|l|}{ PASSERIFORMES } \\
\hline & Mimidae & Mimus saturninus (Lichtenstein, 1823) & sabiá-do-campo \\
\hline & & Coereba flaveola (Linnaeus, 1758) & cambacica \\
\hline \multicolumn{4}{|l|}{ PASSERIFORMES } \\
\hline \multirow[t]{8}{*}{ Thraupidae } & & Nemosia pileata (Boddaert, 1783) & saíra-de-chapéu-preto \\
\hline & & Thlypopsis sordida (D’Orbigny \& Lafresnaye, 1837) & saí-canário \\
\hline & & Lanio cucullatus (Statius Müller, 1776) & tico-tico-rei \\
\hline & & Tangara sayaca (Linnaeus, 1766) & sanhaçu-cinzento \\
\hline & & Tersina viridis (Illiger, 1811) & saí-andorinha \\
\hline & & Dacnis cayana (Linnaeus, 1766) & saí-azul \\
\hline & & Hemithraupis guira (Linnaeus, 1766) & saíra-de-papo-preto \\
\hline & & Conirostrum speciosum (Temminck, 1824) & figuinha-de-rabo-castanho \\
\hline \multicolumn{4}{|l|}{ PASSERIFORMES } \\
\hline \multirow[t]{4}{*}{ Emberizidae } & & Zonotrichia capensis (Müller, 1776) & tico-tico \\
\hline & & Ammodramus humeralis (Bosc, 1792) & tico-tico-do-campo \\
\hline & & Volatinia jacarina (Linnaeus, 1766) & tiziu \\
\hline & & Sporophila caerulescens (Vieillot, 1823) & coleirinho \\
\hline \multicolumn{4}{|l|}{ PASSERIFORMES } \\
\hline & Parulidae & Geothlypis aequinoctialis (Gmelin, 1789) & pia-cobra \\
\hline & & Basileuterus flaveolus (Baird, 1865) & canário-do-mato \\
\hline \multicolumn{4}{|l|}{ PASSERIFORMES } \\
\hline & Icteridae & Icterus cayanensis (Linnaeus, 1766) & encontro \\
\hline \multicolumn{4}{|l|}{ PASSERIFORMES } \\
\hline & Fringillidae & Euphonia chlorotica (Linnaeus, 1766) & fim-fim \\
\hline
\end{tabular}


VARANDA, E.M. et al. Conectividade em ZA de UC

Tabela II.3. Herpetofauna registrada na área da Zona de Amortecimento da Estação Ecológica de Ribeirão Preto.

Table II.3. Herpetofauna recorded in the Buffer Zone area of the Ribeirão Preto Ecological Station.

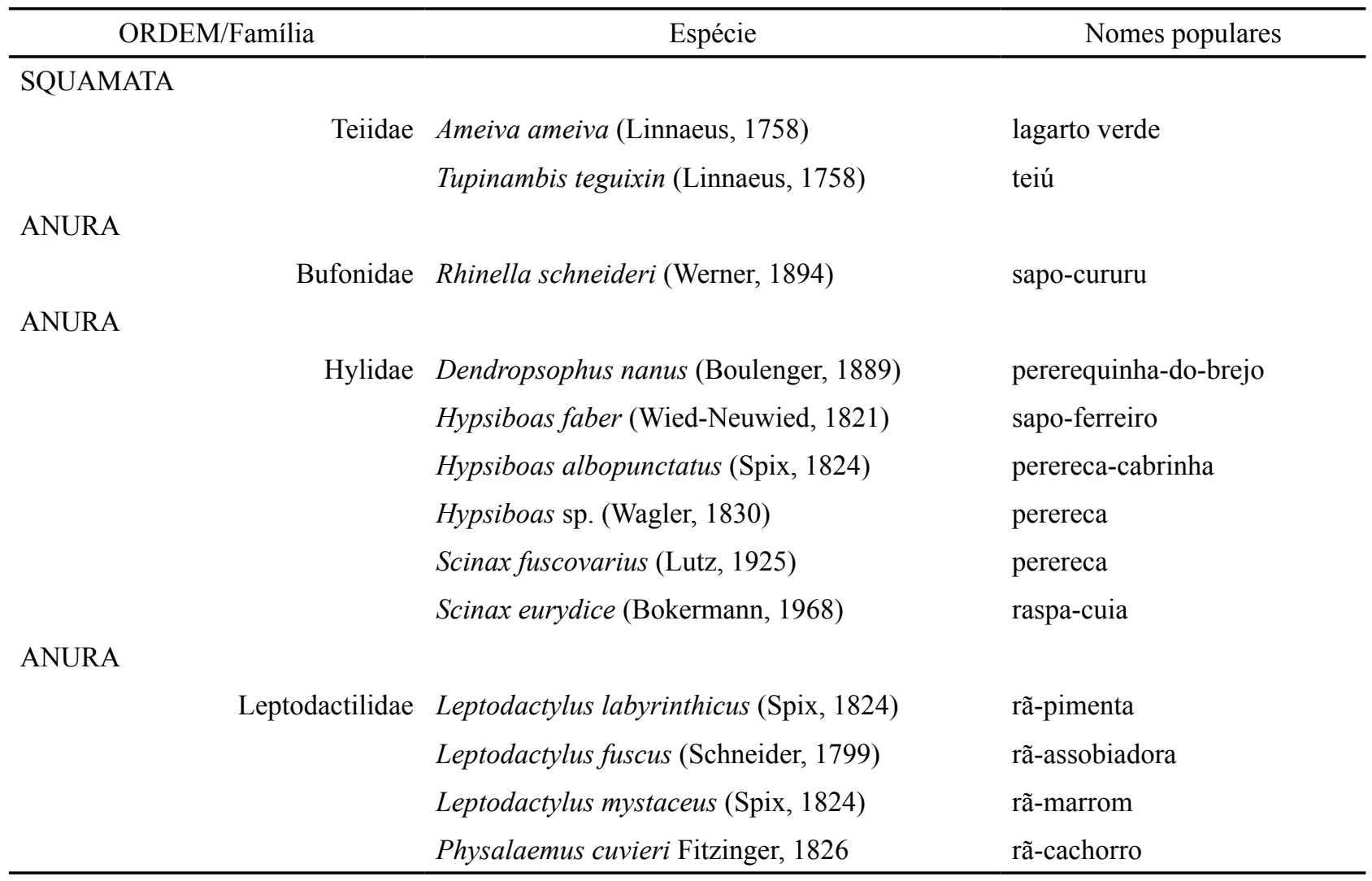


Tabela II.4. Famílias e espécies botânicas identificadas nos fragmentos florestais presentes na Zona de Amortecimento da Estação Ecológica de Ribeirão Preto (SP). *espécies encontradas apenas no Fragmento 1 (dados de Camargo, 2008), **espécies encontradas no fragmento 1 e no fragmento 2 e/ou 3.

Table II.4. Botanical families and species recorded in the forest remnants present in the Buffer Zone of the Ribeirão Preto Ecological Station (SP). *species found only in remnant \#1 (Camargo data, 2008), ${ }^{* *}$ species found in remnant $\# 1$ and remnants \#2 and/or 3 (see remnants location in the Figure 2).

\begin{tabular}{|c|c|}
\hline Famílias/Espécies & Nomes populares \\
\hline \multicolumn{2}{|l|}{ ANACARDIACEAE } \\
\hline Astronium graveolens Jacq.** & guaritá \\
\hline Schinus molleoides Vell. & aroeira-branca \\
\hline Mangifera indica $\mathrm{L}$. & manga, exótica \\
\hline \multicolumn{2}{|l|}{ ANNONACEAE } \\
\hline Duguetia lanceolata A.St. -Hil.** & pindaíba \\
\hline Rolinia sp * & araticum \\
\hline \multicolumn{2}{|l|}{ APOCYNACEAE } \\
\hline Aspidosperma cylindrocarpon Müll. Arg.* & peroba-poca \\
\hline Aspidosperma polyneuron Müll. Arg.* & peroba-rosa \\
\hline Aspidosperma ramiflrum Müll. Arg. * & matiambu \\
\hline \multicolumn{2}{|l|}{ ARALIACEAE } \\
\hline Didimopanax morototonii (Aubl.) Dene. et Planch.* & morototó \\
\hline \multicolumn{2}{|l|}{ ARECACEAE } \\
\hline Syagrus romanzoffiana (Cham.) Glassman * & jerivá \\
\hline \multicolumn{2}{|l|}{ ASTERACEAE } \\
\hline \multicolumn{2}{|l|}{ Bidens gardneri Baker } \\
\hline \multicolumn{2}{|l|}{ BIGNONIACEAE } \\
\hline Tabebuia heptaphylla (Vell.) Toledo & ipê roxo \\
\hline \multicolumn{2}{|l|}{ Tabebuia sp* } \\
\hline Tecoma stans (L.) Juss. ex Kunth & ipê-de-jardim, exótica \\
\hline Zeyheria tuberculosa (Vell.) Bureau ex Verl * & ipê-tabaco bolsa-de-pastor \\
\hline \multicolumn{2}{|l|}{ BORAGINACEAE } \\
\hline Cordia sellowiana Cham.)* & chá-de-bugre, louro-mole \\
\hline Trema micranta (L.) Blume * & grandiúva, pau-pólvora \\
\hline \multicolumn{2}{|l|}{ CARICACEAE } \\
\hline Jacaratia spinosa (Aubl.) A.DC. * & jaracatiá \\
\hline \multicolumn{2}{|l|}{ CELASTRACEAE } \\
\hline Maytenus robusta Reissek * & cafezinho, coração-de-bugre \\
\hline \multicolumn{2}{|l|}{ CHRYSOBALANACEAE } \\
\hline Licania kunthiana Hook. F. & marinheiro \\
\hline \multicolumn{2}{|l|}{ CYPERACEAE } \\
\hline Cyperus ferax Rich. & \\
\hline Cyperus sp. & \\
\hline
\end{tabular}

continua to be continued 
VARANDA, E.M. et al. Conectividade em ZA de UC

continuação - Tabela II.4

continuation - Table II.4

\begin{tabular}{|c|c|}
\hline Famílias/Espécies & Nomes populares \\
\hline \multicolumn{2}{|l|}{ EUPHORBIACEAE } \\
\hline Actinostemon concepcionis (Chodat. \& Hassl.) Hochr.* & fedorenta \\
\hline Alchornea glandulosa Poepp. \& Engl. * & tapiá \\
\hline Croton floribundus Spreng. * & capixingui \\
\hline Croton piptocalix Müll. Arg.* & caixeta \\
\hline Croton urucurana Baill.* & sangra-d'água \\
\hline Sapium glandulatum (Vell.) Pax * & mata-olho, teiteiro \\
\hline \multicolumn{2}{|l|}{ Sebastiania sp* } \\
\hline \multicolumn{2}{|l|}{ FABACEAE } \\
\hline \multicolumn{2}{|l|}{ Caesalpinioideae } \\
\hline Copaifera langsdorffii Desf. ** & copaíba, óleo-de-copaíba \\
\hline Holocalyx balansae Micheli** & alecrim-de-campinas \\
\hline Hymenaea courbaril L.** & jatobá \\
\hline Pterogyne nitens Tul.** & amendoim \\
\hline Schizolobium parahyba (Vell.) Blake ** & guapuruvu \\
\hline Senna macranthera (DC. ex Collad.) H. S. Irwin \& Barn.* & pau-fava \\
\hline Bauhinia sp ** & pata-de-vaca \\
\hline \multicolumn{2}{|l|}{ FABOIDEAE } \\
\hline Centrolobium tomentosum Guillem. ex Benth. & araribá \\
\hline Dalbergia miscolobium Benth. * & sapuvussu, caviúna \\
\hline \multicolumn{2}{|l|}{ Machaerium $\mathrm{sp}$} \\
\hline Machaerium stipitatum (DC.) Vogel * & sapuva \\
\hline Machaerium villosum Vogel * & jacarandá-paulista \\
\hline Platycyamus regnelii Benth. ** & pau-pereira \\
\hline \multicolumn{2}{|l|}{ Sweetia fruticosa Spreng. } \\
\hline \multicolumn{2}{|l|}{ MIMOSOIDEAE } \\
\hline Acacia polyphylla DC. * & monjoleiro \\
\hline Albizia niopoides (Spruce ex Benth.) Burkart & farinha-seca \\
\hline Anadenanthera macrocarpa (Benth.) Brenan & angico \\
\hline Enterolobium contortisiliquum (Vell.) Morong & tamboril \\
\hline Inga $\mathrm{sp} *$ & ingá \\
\hline \multicolumn{2}{|l|}{ Mimosaceae $\mathrm{sp} 1^{*}$} \\
\hline \multicolumn{2}{|l|}{ Mimosaceae $\mathrm{sp} 2 *$} \\
\hline Myroxylon peruiferum L.f. ** & cabreúva \\
\hline \multicolumn{2}{|l|}{ Leguminosae 1} \\
\hline LAMIACEAE & \\
\hline Hyptis sp & \\
\hline
\end{tabular}

continua

to be continued 
VARANDA, E.M. et al. Conectividade em ZA de UC

continuação - Tabela II.4

continuation - Table II.4

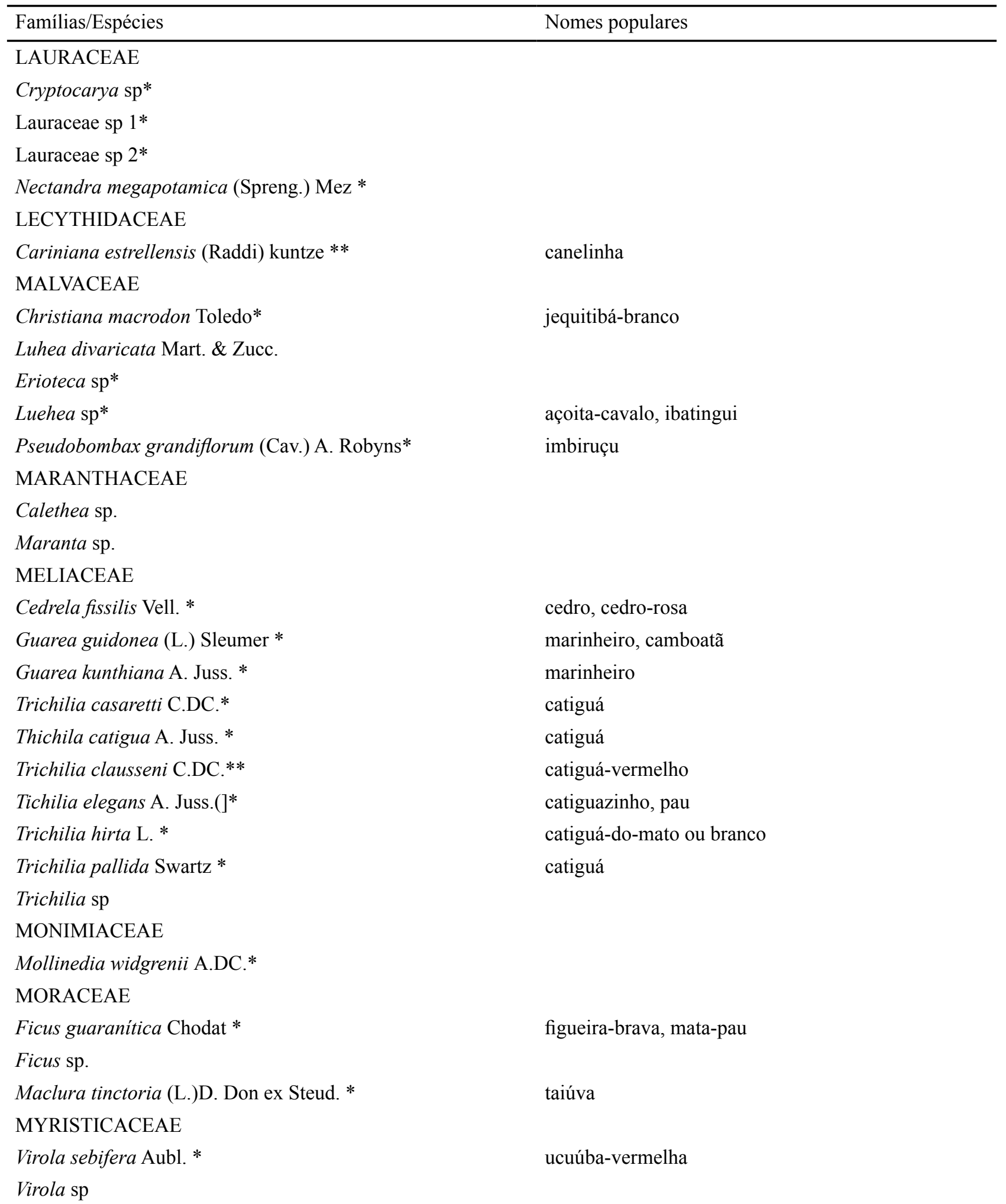

continua to be continued 
VARANDA, E.M. et al. Conectividade em ZA de UC

continuação - Tabela II.4

continuation - Table II.4

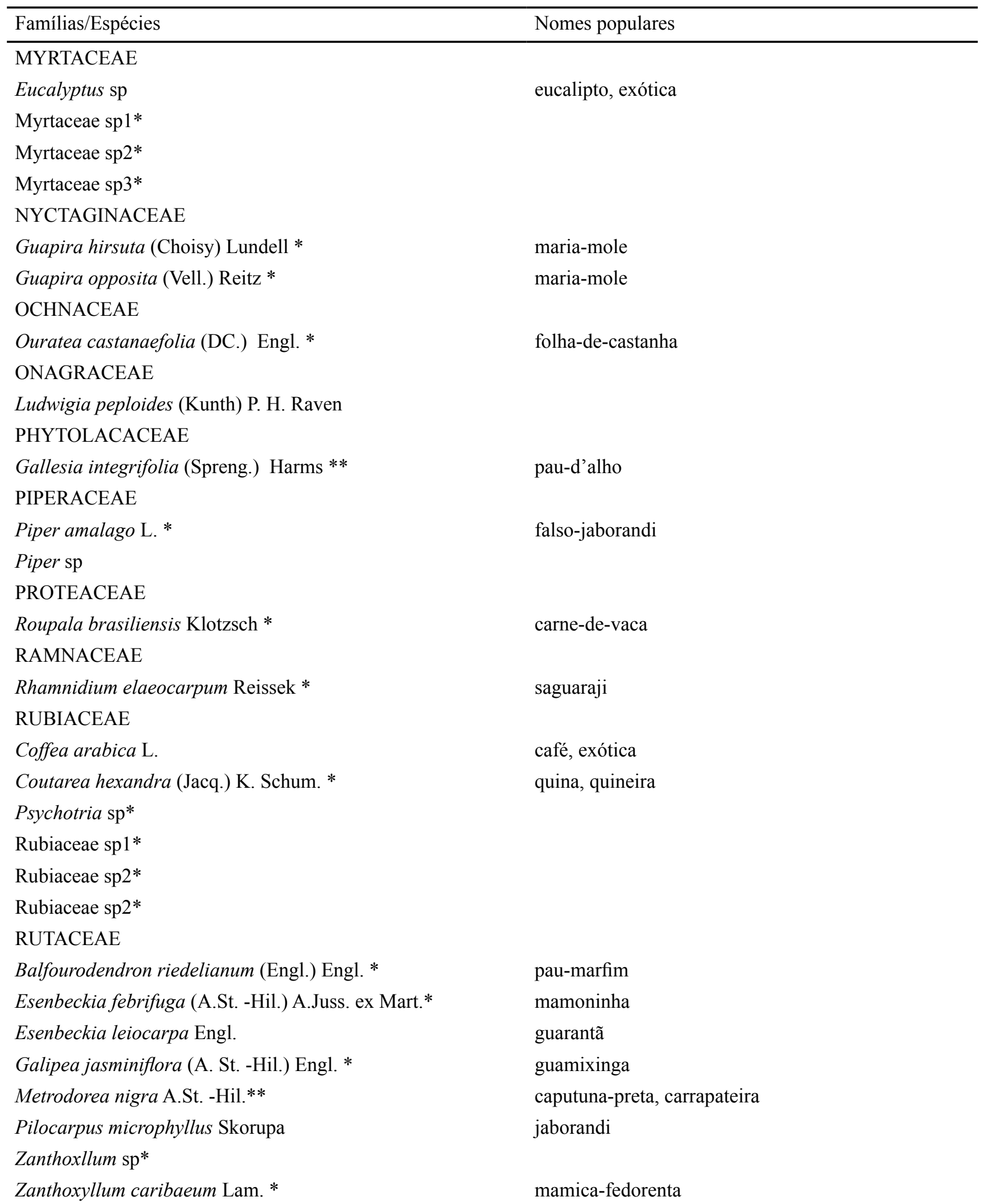

continua

to be continued 
VARANDA, E.M. et al. Conectividade em ZA de UC

continuação - Tabela II.4

continuation - Table II.4

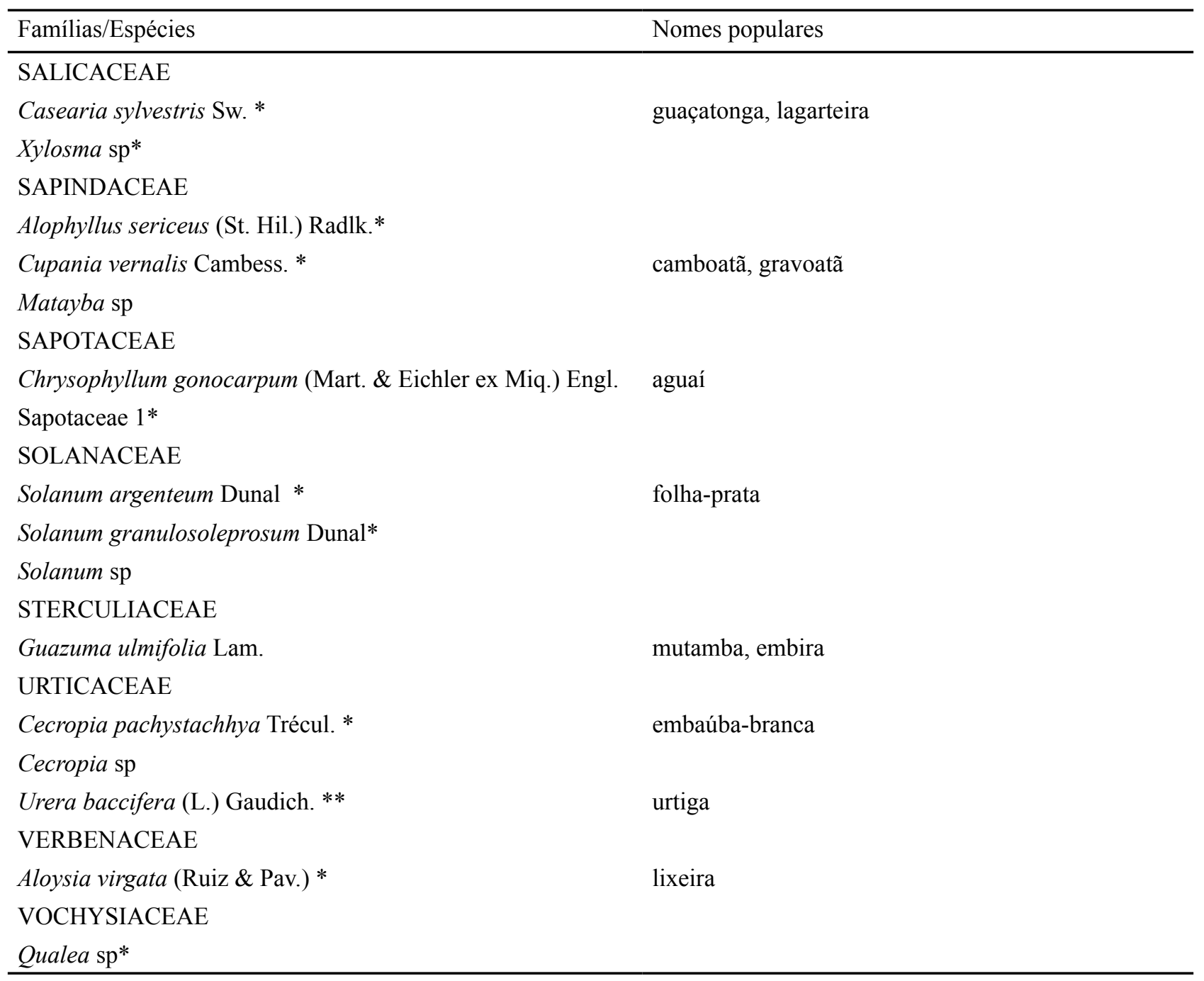


VARANDA, E.M. et al. Conectividade em ZA de UC

\section{Anexo II}

\section{Formulário utilizado para a elaboração de projetos individuais de restauração de áreas degradadas localizadas na Zona de Amortecimento da EERP}

Identificação da Propriedade:

\begin{tabular}{|l|}
\hline Proprietário: \\
\hline Propriedade: \\
\hline Área total: \\
\hline Endereço do Imóvel: \\
\hline Bairro/Setor Micula: \\
\hline Município Região: Ribeirão Preto \\
\hline
\end{tabular}

Localização no Mapa:

Objetivo: Adequar a subzona .... - .... metros do Entorno Imediato da Estação Ecológica de Ribeirão Preto Mata de Santa Tereza - inseridos na zona de amortecimento segundo critérios do Plano de Manejo da Unidade de Conservação aprovado em 23 de março de 2011.

Caracterização da área:

Diagnóstico da área da propriedade inserida na Subzona ....

1. Área:

2. Edificações: ( ) Sim ( ) Não

3. Tipo?

4. Instalação de equipamentos públicos (saneamento, rede elétrica) ( ) Sim ( ) Não

5. Cultivo agrícola:

6. Espécies Florestais Nativas:

7. Espécies Florestais Invasoras:

8. Fauna: ( ) Sim () Não

9. Existência de APP: ( ) Sim () Não

10. Processos erosivos presentes: ( ) Sim () Não

Indicação específica das estratégias de adequação:

Espécies que serão utilizadas:

Espaçamento:

Operações/ Cronograma de operações/ Planilha Orçamentária

Lista de espécies indicadas na subzona ... da Zona de Amortecimento da Mata de Santa Tereza, município de Ribeirão Preto (SP). 


\section{REFERÊNCIAS BIBLIOGRÁFICAS}

BORGES, L.A.C. et al. Áreas de preservação permanente na legislação ambiental brasileira. Ciência Rural, v. 41, n. 7, p. 1202-1210, 2011.

BRASIL. Lei ${ }^{\circ} 4.771 / 1965$, de 15 de setembro de 1965. Institui o novo Código Florestal. Diário Oficial dos Estados Unidos do Brasil, ano 103, $\mathrm{n}^{\circ}$ 117, 16 set. 1965. Seção I, Parte I, p. 9531. Disponível em: $<$ http://www.planalto.gov.br/ccivil_03/ leis/14771.htm>. Acesso em: 18 ago. 2011.

BRASIL. Lei $\mathrm{n}^{\circ}$ 9.985, de 18 de julho de 2000. Regulamenta o art. 225, § 1o, incisos I, II, III e VII da Constituição Federal, institui o Sistema Nacional de Unidades de Conservação da Natureza e dá outras providências. Diário Oficial da União, v. 138, 19 jun. 2000. Seção 1, p. 45. Disponível em: $<$ http://www.planalto.gov.br/ccivil_03/leis/19985.htm>. Acesso em: 15 fev. 2011.

BRASIL. Ministério do Meio Ambiente - MMA. Lista nacional das espécies da fauna brasileira ameaçadas de extinção. 2014. Disponível em: $<$ http://www.icmbio.gov.br/portal/biodiversidade/ fauna-brasileira/lista-de-especies.html $>$. Acesso em: 7 nov. 2014.

CAMARA, G. et al. Spring: integrating remote sensingand GIS by object-oriented data modelling. Computers \& Graphics, v. 20, n. 3, p. 395-403, 1996.

CAMARGO, U.M. Grupos ecológicos da vegetação arbórea de um trecho degradado de Floresta Estacional Semidecidual - Mata de Santa Tereza - no município de Ribeirão Preto, SP, Brasil. 2008. 49 f. Monografia (Graduação em Ciências Biológicas) - Faculdade de Filosofia, Ciências e Letras de Ribeirão Preto, Universidade de São Paulo, Ribeirão Preto.

EMPRESA BRASILEIRA DE PESQUISA AGROPECUÁRIA - EMBRAPA. Banco de dados climáticos do Brasil. Disponível em: $<$ http://www.bdclima.cnpm.embrapa.br $>$. Acesso em: 15 nov. 2011.

FAHRIG, L. Effects of habitat fragmentation on biodiversity. Annual Review of Ecology and Systematics, v. 34, p. 487-515, 2003.
FALCY, M.R.; ESTADES, C.F. Effectiveness of corridors relative to enlargement of habitat patches. Conservation Biology, v. 21, n. 5, p. 1341-1346, 2007.

FISCHER, J.; LINDENMAYER, D.B.; MANNING, A.D. Biodiversity, ecosystem function, and resilience: ten guiding principles for commodity production landscapes. Frontiers in Ecology and the Environment, v. 4, n. 2, p. 80-86, 2006.

GROOM, M.J.; MEFFE, G.K.; CARROLL, C.R. Principles of conservation biology. Massachusetts: Sinauer Associates, 2006. 779 p.

HADDAD, N.M. Corridor and distance effects on interpatch movements: a landscape experiment with butterflies. Ecological Applications, v. 9, n. 2, p. 612-622, 1999.

INSTITUTO BRASILEIRO DE GEOGRAFIA E ESTATÍSTICA - IBGE. Censo Populacional 2010. Disponível em: $<$ http://www.ibge.gov.br/ home/estatistica/populacao/censo2010/tabelas_pdf/ total_populacao_sao_paulo.pdf $>$. Acesso em: 1 abr. 2013.

INTERNATIONAL UNION FOR CONSERVATION OF NATURE - IUCN. 2014. Red list of threatened species. Disponível em: $<$ http://www.iucnredlist.org>. Acesso em: 6 de janeiro de 2015.

LEONEL, C. et al. Plano de Manejo da Estação Ecológica de Ribeirão Preto: volume principal e anexos. Ribeirão Preto: Secretaria do Meio Ambiente. Disponível em: $<$ http://fflorestal.sp.gov. br/files/2012/01/EERP-Vol-principal.pdf $>$. Acesso em: 19 jan. 2015.

LINDENMAYER, D.B.; FISCHER, J. Habitat fragmentation and landscape change. Washington, D.C.: Island Press, 2006. 329 p.

LOEBMANN, D. Guia ilustrado: os anfíbios da região costeira do extremo sul do Brasil. Pelotas: USEB, 2005. 76 p. (Manuais de Campo USEB, 4).

LOISELLE, B.A.; BLACKE, J.G. Population variation in a tropical bird community: implications for conservation. BioScience, v. 42, p. 838-845, 1992. 
LOPES, A.V. et al. Long-term erosion of tree reproducyive trait diversity in edge-dominated Atlantic forest fragments. Biological Conservation, v. 142, n. 6, p. 1154-1165, 2009.

MANNING, A.D.; FISCHER, J.; LINDENMAYER, D.B. Scattered trees are keystone structures - implications for conservation. Biological Conservation, v. 132, p. 311-321, 2006.

MARTINELLI, G.; MORAES, M.A. (Ed.). Livro vermelho da flora brasileira. Rio de Janeiro: Andrea Jakobson Estúdio: Instituto de Pesquisas Jardim Botânico do Rio de Janeiro, 2013. 1100 p.

McGARIGAL, K. et al. Fragstats: spatial pattern analysis program for categorical maps. Computer software program produced by the authors at the University of Massachusetts, Amherst, 2002. Disponível em: <http://www.umass.edu/landeco/ research/fragstats/fragstats.html $>$. Acesso em: 25 jul. 2011.

METZGER, J.P. O Código Florestal tem base científica? Natureza \& Conservação v. 8, n.1, p. 1-5, 2010.

. et al. Brazilian law: full speed in reverse? Science, v. 329, p. 276-277, 2010.

MYERS, N. et al. Biodiversity hotspots for conservation priorities. Nature, v. 403, p. 853-858, 2000.

NAIMAN, R.J.; DECAMPS, H.; POLLOCK, M. The role of riparian corridors in maintaining regional biodiversity. Ecological Applications, v. 3, n. 2, p. 209-212, 1993.

PARDINI, R. et al. Beyond the fragmentation threshold hypothesis: regime shifts in biodiversity across fragmented landscapes. Plos One, v. 5, n. 10, e.13666,2010.Disponívelem:<http://www.plosone.org/ article/info\%3 Adoi\%2F $10.1371 \% 2$ Fjournal. pone.0013666>. Acesso em: 25 jun. 2011.

REIS, N. R. et al. (Ed.). Mamíferos do Brasil. 2. ed. Londrina: [s.n.], 2011. 439 p. Disponível em: $<$ http://www.uel.br/pos/biologicas/pages/arquivos/ pdf/Livro-completo-Mamiferos-do-Brasil.pdf $>$. Acesso em: 16 set. 2014.

RIBEIRO, M.C. et al. The Brazilian Atlantic Forest: how much is left, and how is the remaining forest distributed? Implications for conservation. Biological Conservation, v. 142, p. 1141-1153, 2009.
RICKETTS, T.H. et al. Pinpointing and preventing imminent extinctions. PNAS, v. 102, n. 51, p. 18497-18501, 2005.

ROSENBERG, D.K.; NOON, B.R; MESLOW, E.C. Biological corridors: form, function, and efficacy. BioScience, v. 47, p. 10, p. 677-687, 1997.

SÃO PAULO (Estado). Decreto Estadual n ${ }^{\circ}$ 60.133, de 7 de fevereiro de 2014. Espécies de vertebrados e invertebrados da fauna silvestre ameaçadas de extinção do Estado de São Paulo. Diário Oficial do Estado de São Paulo, Poder Executivo, v. 124, 8 fev. 2014. Seção I, 27, p. 25-32, 2014.

SOS MATA ATLÂNTICA. 2013. Disponível em: $<$ http://www.sosma.org.br/14622/divulgadosnovos-dados-sobre-a-situacao-da-mata-atlantica>. Acesso em: 29 jul. 2014.

TEWKSBURY, J.J. et al. Corridors affect plants, animal, and their interactions in fragmented landscapes. PNAS, v. 99, n. 20, p. 12923-12926, 2002.

TILMAN, D. et al. Habitat destruction and the extinction debt. Nature, v. 371, p. 65-66, 1994.

VIANA, V.M.; PINHEIRO, L.A.F.V. Conservação da biodiversidade em fragmentos florestais. Série Técnica IPEF, v. 12, n. 32, p. 25-42, 1998.

WILLIS, E.O. The composition of avian communities in remanescent woodlots in southern Brazil. Papéis Avulsos de Zoologia, v. 33, p. 1-25, 1979.

WILSON, D.E.; REEDER, D.M. Mammals species of the world: a taxonomic and geographic reference. $3^{\text {th }}$ ed. Washington, D.C.: Smithsoniam Institution Press, 2005. 2000 p.

WRIGHT, S.J. et al. Poachers alter mammal abundance, seed dispersal, and seed predation in a neotropical forest. Conservation Biology, v. 14, p. 227-239, 2000. 